\title{
The Cost of Providing District-Level Surgery in Malawi
}

\author{
Dennis Cornelissen ${ }^{1} \cdot$ Gerald Mwapasa $^{2} \cdot$ Jakub Gajewski $^{3} \cdot$ Tracey McCauley $^{3}$ • \\ Eric Borgstein $^{2} \cdot$ Ruairi Brugha $^{3} \cdot$ Leon Bijlmakers ${ }^{1}$
}

Published online: 8 August 2017

(C) The Author(s) 2017. This article is an open access publication

\begin{abstract}
Background Three district hospitals in Malawi that provide essential surgery, which for many patients can be lifesaving or prevent disability, formed the setting of this costing study.

Methods All resources used at district hospitals for the delivery of surgery were identified and quantified. The hospital departments were divided into three categories of cost centres-the final cost centre, intermediate and ancillary cost centres. All costs of human resources, buildings, equipment, medical and non-medical supplies and utilities were quantified and allocated to surgery through step-down accounting.

Results The total cost of surgery, including post-operative care, ranged from US\$329,000 per year to more than twice that amount at one of the hospitals. At two hospitals, it represented $16-17 \%$ of the total cost of running the hospital. The main cost drivers of surgery were transport and inpatient services, including catering. The cost of a C-section ranged from \$ 164 to 638 that of a hernia repair from \$ 137 to 598. Evacuations from uterus were cheapest mainly because of the shorter duration of patient stay.

Conclusion Low bed occupancy rates and utilisation rates of the operating theatres suggest overcapacity but may also indicate a potential to scale up surgery. This may be achieved by adding surgical staff, although there may be rate-limiting steps, such as demand for surgery in the community or capacity to provide anaesthesia. If a scale-up of surgery cannot be realised, hospital managers may be forced to reduce the number of beds, reorganise wards and/or reallocate staff to achieve better economies of scale.
\end{abstract}

Electronic supplementary material The online version of this article (doi:10.1007/s00268-017-4166-5) contains supplementary material, which is available to authorized users.

Leon Bijlmakers

Leon.Bijlmakers@radboudumc.nl

1 Radboud University Medical Centre Netherlands, Geert Grooteplein Zuid 10, 6525 GA Nijmegen, The Netherlands

2 College of Medicine, University of Malawi, Mahatma Gandhi, Blantyre, Malawi

3 Royal College of Surgeons in Ireland, 123 St Stephens Green, Dublin 2, Ireland

\section{Introduction}

Surgery has for long been neglected in low- and middleincome countries (LMIC), as a result of which more than 95\% of the population in South Asia and most of subSaharan Africa do not have access to basic surgical care [1]. In 2010, an estimated 16.9 million lives were lost from conditions needing surgical care; this represented almost a third (32.9\%) of all deaths worldwide [2]. Only 6\% of the 313 million procedures undertaken each year occur in the poorest countries, where over a third of the world's population lives, and 143 million additional surgical procedures are needed each year to save lives and prevent disability [3]. 
One of the four working groups of the Lancet Commission on Global Surgery focused on the economics and financing of surgical and anaesthesia care. The group has shown that without an accelerated investment in the scaleup of surgery, LMIC will face enormous losses in economic productivity which may accumulate to around US\$ 12 trillion between 2015 and 2030 [3]. The annual value of lost economic output secondary to surgical conditions will have a profound effect, especially in LMIC, where by the year 2030 surgical conditions could reduce annual growth in gross domestic products by almost $2 \%$.

While the need for functional health systems and the structural availability of human resources, infrastructure and supplies to deliver essential surgery is clear, financing is uncertain in many LMIC and financial mechanisms inadequate. Moreover, the way health services are organised and financed in most countries does not allow a good insight into how much it actually costs to provide essential surgery, leave alone how much extra money would be required to scale up surgery in order to meet the demand.

Malawi's national health care system is organised around district hospitals which provide first-level services to patients who are referred by primary health care units. These district hospitals in turn refer certain patients to one of the four central hospitals which provide specialist care. The bulk of the clinical care at district hospitals is provided by clinical officers. These are non-physician clinicians who, amongst many other tasks, undertake obstetric, gynaecological and basic general surgery, of which the post-operative outcomes are comparable to procedures that are performed by medical officers [4, 5]. Since 2013, the University of Malawi College of Medicine has been providing training in surgery to clinical officers, through a BSc in surgery, that received funding during the first four years through the Clinical Officers Surgical Training in Africa project (COST-Africa, see www.costafrica.eu). This matched pair randomised controlled trial (RCT) research project, which was funded by the European Union under its Framework Programme 7, aimed to demonstrate the effectiveness and cost-effectiveness of increasing the surgical capacity of non-physician clinicians in rural Malawi and Zambia. The trial was registered in the ISRCTN registry on 27 February 2014, under registration number 66099597.

This paper identifies the resources and estimates the costs of delivering surgery at district hospitals in Malawi; it expresses the cost of surgery as a percentage of the total annual cost of running a district hospital and calculates unit costs of selected surgical procedures.

In order to determine the annual costs of providing surgery, two questions guided the study:
(1) What is the cost of surgery, taking into account not just resources that are used in the operating theatre (OT) and on the surgical wards, but also inputs such as staff time and transport facilities, that are shared with other hospital departments for services other than surgery?

(2) What are the unit costs of common surgical procedures conducted at district hospitals in Malawi?

Three district hospitals formed the setting of the study. Each had received two COST-Africa sponsored BSc students, who were undergoing in-service training through weekly visits from surgeon trainers. The hospitals were selected for this economic analysis out of eight candidates, mainly for reasons of convenience: Mangochi district hospital $(\mathrm{MaDH})$, Mulanje district hospital $(\mathrm{MuDH})$ and Nsanje district hospital (NsDH), all situated in the country's southern region. The three hospitals are similar in terms of infrastructure and service packages offered. Each has one main operating theatre for major surgery cases and a smaller theatre for minor cases; in addition, $\mathrm{MuDH}$ and $\mathrm{NsDH}$ each have a small operating theatre within the outpatient department (OPD) for minor surgery. None of the three hospitals have designated surgical wards.

\section{Materials and methods}

OT registers were used to count the number of surgical procedures performed over a 12-month period (from 1 July 2013 to 30 June 2014) and categorise them into four types: pregnancy-related and obstetric surgery, emergency and disability preventive surgery, injury-related surgery and other major or minor procedures, as shown in Box 1.

Step-down accounting was applied for costing. This is a relatively simple method that is recommended by the World Health Organization for generating costs and unit cost data at the health facility level in low- and middleincome countries. It identifies and quantifies the various inputs used by a health facility, estimates the total cost of each of these inputs, allocates them to cost centres and links them to the various services that are provided [6, 7]. It involves six steps of which detailed descriptions are given in Online Resource 1: (1) define the final product(s) of interest; (2) define the final, intermediate and ancillary cost centres; (3) identify all inputs and calculate the full costs of each input; (4) assign inputs to the appropriate cost centres; (5) allocate all direct costs and appropriate proportions of the costs of the inputs used at ancillary and intermediate cost centres to the final cost centre; and (6) calculate the unit cost for each service provided at the final cost centre.

Data collection took place between November 2014 and March 2015, and all data pertain to the financial year July 
Box 1 Types of surgical procedures by category

\begin{tabular}{|c|c|c|c|}
\hline Pregnancy-related and obstetric surgery & $\begin{array}{l}\text { Emergency and disability-preventive } \\
\text { surgery }\end{array}$ & Injury-related surgery & Other surgery \\
\hline $\begin{array}{l}\text { Caesarean section } \\
\text { Hysterectomy } \\
\text { Repair of ruptured uterus } \\
\text { Salpingectomy } \\
\text { Elective bilateral tubal ligation (BTL) } \\
\text { BTL in combination with a caesarean } \\
\text { section } \\
\text { Dilatation and curettage/manual vacuum } \\
\text { aspiration } \\
\text { Evacuation of uterus } \\
\text { Other major gynaecological procedures } \\
\text { Other minor gynaecological procedures }\end{array}$ & $\begin{array}{l}\text { Inguinal herniotomy/herniorrhaphy } \\
\text { Femoral hernia repair } \\
\text { Other hernia's (umbilical, epigastric, } \\
\text { incisional) } \\
\text { Hydrocoele repair } \\
\text { Correction of torsion } \\
\text { Prostatectomy } \\
\text { Appendectomy } \\
\text { Gastro-intestinal resection and } \\
\text { anastomosis } \\
\text { Explorative/other laparotomy } \\
\text { Amputation/disarticulation } \\
\text { Cataract removal } \\
\text { Circumcision }\end{array}$ & $\begin{array}{l}\text { Manipulation under } \\
\quad \text { anaesthesia } \\
\text { Suturing } \\
\text { Debridement } \\
\text { Skin grafting, dressing }\end{array}$ & $\begin{array}{l}\text { Other major procedures, } \\
\text { such as } \\
\text { Vesico-vaginal fistula } \\
\text { repair } \\
\text { Myomectomy } \\
\text { Decompression } \\
\text { Minor procedures } \\
\text { Foreign body removal } \\
\text { Incision and drainage } \\
\text { Excision }\end{array}$ \\
\hline
\end{tabular}

2013-June 2014. Online Resource 1 also describes the electronic model that was constructed to enter the data into spreadsheets, allocate costs to surgery, calculate unit costs of individual surgical procedures and estimate the cost implications of various alternatives for scaling up districtlevel surgery.

\section{Results}

The key parameters of the three hospitals involved in the study are shown in Table 1.

Of note is the low bed occupancy rate at $\mathrm{NsDH}(17 \%$ compared to $50-58 \%$ at the other two hospitals), indicating overcapacity or under-utilisation of inpatient services. The total staff complement in each hospital ranged from 302 (at $\mathrm{NsDH})$ to $378(\mathrm{MaDH})$ of which about two-thirds were support staff such as hospital attendants, kitchen staff, mortuary attendants, grounds men and security guards. Clinical officers were the largest cadre of clinicians at these district hospitals, ranging from 17 to 24 per hospital, of which two (in $\mathrm{MaDH}$ and $\mathrm{NsDH}$ ) or three (in $\mathrm{MuDH}$ ) received additional surgical training through COST-Africa. $\mathrm{MaDH}$ had five medical officers, compared with two at $\mathrm{MuDH}$ and just one at $\mathrm{NsDH}$. MaDH had only one trained anaesthetist versus three at the other two hospitals. In spite of its higher bed occupancy rate, $\mathrm{MaDH}$ had the fewest qualified nursing officers. $\mathrm{MaDH}$ and $\mathrm{MuDH}$ had much higher annual ORT budgets ${ }^{1}$ to cover recurrent expenditure

\footnotetext{
${ }^{1}$ Other recurrent transactions: a term used for the Government budget allocation that hospitals and districts use to cover various types of recurrent expenditure.
}

than $\mathrm{NsDH}$, but the latter hospital compensated this to some extent with more external funding (from donors), which brought in almost as much as the Government ORT funding.

\section{Surgical services and other hospital output}

Table 2 shows the volume of patient services provided in the 2013/14 financial year per hospital, in terms of admissions and inpatient days for the main categories of surgical procedures.

$\mathrm{MaDH}$ conducted the largest number of surgical procedures (2462 cases), of which $84 \%$ involved pregnancyrelated and obstetric surgery. MuDH came second (with just over 1900 cases of surgery), while $\mathrm{NsDH}$ had the smallest number (just over 1400 cases). The latter hospital had relatively more injury-related surgery (20\% of all cases, compared with 4-6\% at the other two hospitals) and more emergency and disability-preventive surgery $(17 \%$ of all cases, compared with $7 \%$ at both $\mathrm{MaDH}$ and $\mathrm{MuDH}$ ), which suggests that the demand for surgery at NsDH is less predictable. Just over half $(53 \%)$ of all surgical cases at $\mathrm{NsDH}$ were for pregnancy-related and obstetric surgery, compared with $80 \%$ at $\mathrm{MuDH}$ and $84 \%$ of major surgical cases at $\mathrm{MaDH}$. The workload in terms of inpatient days also differed between the three hospitals. While NsDH had the smallest number of surgical admissions, it had the largest number of surgical inpatient days.

In terms of patient load other than for surgery, $\mathrm{MaDH}$ was two to three times as busy as $\mathrm{NsDH}$, having almost twice as many OPD visits, almost thrice as many admissions of patients other than for surgery, and five times as many non-surgical inpatient days. 
Table 1 Key parameters of Mangochi, Mulanje and Nsanje district hospitals in 2013/14

\begin{tabular}{|c|c|c|c|}
\hline & Ma DH & $\mathrm{Mu} \mathrm{DH}$ & Ns DH \\
\hline \multicolumn{4}{|l|}{ Infrastructure } \\
\hline Surface area (in $\mathrm{m}^{2}$ ) & 5439 & 4617 & 5364 \\
\hline Number of theatres inside the OT complex & 2 & 2 & 2 \\
\hline Number of theatres located at the OPD & 0 & 1 & 1 \\
\hline Hospital beds & 263 & 244 & 228 \\
\hline Bed occupancy rate ${ }^{\mathrm{a}}$ & $58 \%$ & $50 \%$ & $17 \%$ \\
\hline Number of wards & 6 & 5 & 6 \\
\hline Number of functional ambulances & 12 & 9 & 9 \\
\hline Shortest route to the nearest central hospital ${ }^{b, c}$ & $127 \mathrm{~km}$ & $61 \mathrm{~km}$ & $173 \mathrm{~km}$ \\
\hline \multicolumn{4}{|l|}{ Staffing (excluding trainees/students and expatriate staff) } \\
\hline Medical officers & 5 & 2 & 1 \\
\hline Clinical officers excluding COST-Africa sponsored CO's & 22 & 19 & 15 \\
\hline COST-Africa CO's & 2 & 3 & 2 \\
\hline Anaesthetists & 1 & 3 & 3 \\
\hline Nursing officers & 7 & 16 & 10 \\
\hline Laboratory and X-ray staff & 7 & 8 & 11 \\
\hline Other (para-)medical staff & 84 & 75 & 39 \\
\hline Administrative staff & 29 & 27 & 28 \\
\hline Other support staff & 221 & 214 & 193 \\
\hline TOTAL members of staff ${ }^{\mathrm{d}}$ & 378 & 367 & 302 \\
\hline \multicolumn{4}{|l|}{ Funding (in US\$) } \\
\hline Government ORT budget ${ }^{\mathrm{e}}$ & 920,407 & 800,301 & 375,986 \\
\hline External funding & 239,431 & 169,800 & 347,262 \\
\hline \multicolumn{4}{|c|}{${ }^{a}$ Bed occupancy rate $(B O R)=$ number of beds times 365 divided by the number of inpatient days over a whole year } \\
\hline \multirow{2}{*}{\multicolumn{4}{|c|}{$\begin{array}{l}\text { b All the three hospitals refer patients who need specialist treatment to Queen Elisabeth central hospital in Blantyre. MaDH also refers patients to } \\
\text { Zomba central hospital, which is nearer but doesn't have the full range of expertise and facilities of a typical referral hospital }\end{array}$}} \\
\hline & & & \\
\hline \multicolumn{4}{|l|}{ c Calculated with Google Maps } \\
\hline \multicolumn{4}{|l|}{${ }^{\mathrm{d}}$ Excluding trainees/students who do not receive salaries } \\
\hline
\end{tabular}

\section{Costs}

The total costs of providing surgery in each of the three hospitals over the 12-months period are presented in Table 3, with a breakdown by cost centre and type of expenditure.

The total cost of surgery at $\mathrm{MaDH}$ is similar to that at MuDH (\$363,000 and \$329,000, respectively, for the whole year), but the distributions are different due to different costs for the two largest cost centres: surgical inpatient services and transport. MuDH has more senior staff on the wards and at the OT, which results in higher salary costs. $\mathrm{MaDH}$ has more vehicles, which largely explains the higher cost of transport.

At $\$ 736,000$, the total cost of surgery at $\mathrm{NsDH}$ is about twice as high as at the other two hospitals; this is mainly due to the much higher cost of surgical inpatient services, and in spite of a much lower inpatient load (as shown in
Table 2), and a slightly lower total bed capacity (Table 1). The longer duration of stay in combination with a low bed occupancy rate $(17 \%)$ makes inpatient services at $\mathrm{NsDH}$ relatively expensive. The cost of ancillary services at $\mathrm{NsDH}$ is also comparatively high, while the direct costs of the operating theatre are somewhat lower than at $\mathrm{MaDH}$ and $\mathrm{MuDH}$, mainly due to lower expenditure on $\mathrm{CO}$ wages and on medication and supplies.

The annual cost of surgery represents $16-17 \%$ of the total cost of the entire hospital for $\mathrm{MaDH}$ and $\mathrm{MuDH}$ (not shown in the table). At NsDH though, $47 \%$ of the total cost of the hospital goes towards surgery or rather to inputs that are supposed to be used for surgery.

The unit cost of the three most common surgical procedures varies considerably amongst the three hospitals, as shown in Table 4. Evacuation from uterus is cheaper than a hernia operation mainly because the former procedure normally does not require the patient to stay at the hospital 
Table 2 Surgical and non-surgical services provided by hospitals over 12 months (2013/14 fiscal year)

\begin{tabular}{|c|c|c|c|c|c|c|c|}
\hline & & \multicolumn{2}{|l|}{$\mathrm{Ma} \mathrm{DH}$} & \multicolumn{2}{|l|}{$\mathrm{Mu} \mathrm{DH}$} & \multicolumn{2}{|l|}{ Ns DH } \\
\hline & & $\begin{array}{l}\text { Surgical } \\
\text { procedures }\end{array}$ & $\begin{array}{l}\text { Inpatient } \\
\text { days }\end{array}$ & $\begin{array}{l}\text { Surgical } \\
\text { procedures }\end{array}$ & $\begin{array}{l}\text { Inpatient } \\
\text { days }\end{array}$ & $\begin{array}{l}\text { Surgical } \\
\text { procedures }\end{array}$ & $\begin{array}{l}\text { Inpatient } \\
\text { days }\end{array}$ \\
\hline \multicolumn{8}{|c|}{ Surgery-related patient services } \\
\hline $\begin{array}{l}\text { Pregnancy-related and obst } \\
\text { surgery }\end{array}$ & & $2060(84 \%)$ & $3048(64 \%)$ & $1526(80 \%)$ & $2351(70 \%)$ & $748(53 \%)$ & $3447(61 \%)$ \\
\hline $\begin{array}{l}\text { Emergency and disability } \\
\text { surgery }\end{array}$ & ventive & $162(7 \%)$ & $725(15 \%)$ & $141(7 \%)$ & $444(13 \%)$ & $243(17 \%)$ & $1254(22 \%)$ \\
\hline Injury-related surgery & & $97(4 \%)$ & $854(18 \%)$ & $113(6 \%)$ & $269(8 \%)$ & $289(20 \%)$ & $841(15 \%)$ \\
\hline Other surgical procedures & & $143(6 \%)$ & $120(3 \%)$ & $133(7 \%)$ & $276(8 \%)$ & $134(9 \%)$ & $116(2 \%)$ \\
\hline \multirow[t]{2}{*}{ Total } & & $2462(100 \%)$ & $4737(100 \%)$ & $1913(100 \%)$ & $3340(100 \%)$ & $1414(100 \%)$ & $5649(100 \%)$ \\
\hline & \multicolumn{2}{|c|}{ Admissions } & \multicolumn{2}{|c|}{ Admissions } & Inpatient days & Admissions & Inpatient days \\
\hline \multicolumn{8}{|c|}{ Non-surgery-related inpatient services } \\
\hline Non-surgical inpatients & 14,582 & \multirow[t]{2}{*}{51,738} & \multicolumn{2}{|c|}{15,234} & 40,767 & 5077 & 10,005 \\
\hline \multicolumn{7}{|l|}{ Outpatient services } & \\
\hline OPD visits & 161,192 & $\mathrm{n} / \mathrm{a}$ & \multicolumn{2}{|c|}{109,828} & $\mathrm{n} / \mathrm{a}$ & 87,610 & $\mathrm{n} / \mathrm{a}$ \\
\hline
\end{tabular}

Table 3 Cost of surgery (in US\$) by cost centre and type of expenditure over 12 months (July 2013-June 2014)

\begin{tabular}{|c|c|c|c|}
\hline & $\mathrm{Ma} \mathrm{DH}$ & $\mathrm{Mu} \mathrm{DH}$ & Ns DH \\
\hline \multicolumn{4}{|c|}{ Direct cost of operating theatre (final cost centre) } \\
\hline Capital items & 14,541 & 11,019 & 10,913 \\
\hline Wages & 26,948 & 37,675 & 26,197 \\
\hline Medication and supplies & 45,753 & 43,757 & 25,195 \\
\hline Subtotal (A) & $87,066(24 \%)$ & $92,269(28 \%)$ & $63,024(9 \%)$ \\
\hline \multicolumn{4}{|c|}{ Cost of intermediate cost centres allocated to surgery } \\
\hline Laboratory & 3933 & 2453 & 5134 \\
\hline Radiology department & 1639 & 2486 & 6449 \\
\hline Wards (surgical inpatient services) & 80,149 & 98,775 & 457,081 \\
\hline Subtotal (B) & $85,721(24 \%)$ & $103,714(31 \%)$ & $468,665(64 \%)$ \\
\hline \multicolumn{4}{|c|}{ Cost of ancillary departments allocated to surgery } \\
\hline Laundry & 864 & 2571 & 5625 \\
\hline Housekeeping, stores and security & 4974 & 4147 & 3764 \\
\hline Maintenance and repairs & 1152 & 2208 & 2751 \\
\hline Utillities & 7165 & 6417 & 21,709 \\
\hline Pharmacy (excl drugs and supplies) & 1277 & 1294 & 1088 \\
\hline Kitchen for staff catering & 5694 & 5329 & 20,918 \\
\hline Transport & 150,888 & 104,493 & 111,551 \\
\hline Management and administration & 2402 & 1972 & 2711 \\
\hline Subtotal (C) & $194,415(52 \%)$ & $133,454(41 \%)$ & $204,295(28 \%)$ \\
\hline Total cost of surgery $(A+B+C)$ & $363,202(100 \%)$ & $329,437(100 \%)$ & $735,985(100 \%)$ \\
\hline
\end{tabular}

for more than a day, while hernia cases remain in hospital for a couple of days (3.0 days on average at $\mathrm{MaDH}$, 2.4 days at $\mathrm{MuDH}, 5.6$ days at $\mathrm{NsDH})$. C-sections are more expensive than hernia operations for the same reason: the higher unit cost is partly due to the longer duration of stay (6.3 days on average for a C-section at $\mathrm{NsDH}$, 5.6 days at $\mathrm{MaDH}, 5.9$ days at $\mathrm{MuDH}$ ). The unit costs of surgical procedures at $\mathrm{NsDH}$ are consistently higher than at the other two hospitals. This is because of the higher total cost which has to be shared amongst fewer patients. 
Table 4 Unit cost of the three most common surgical procedures (in US\$)

\begin{tabular}{lrcl}
\hline & Ma DH & Mu DH & Ns DH \\
\hline Caesarean section & 164 & 251 & 638 \\
Evacuation from uterus & 57 & 72 & 143 \\
Hernia procedure & 137 & 164 & 598 \\
\hline
\end{tabular}

\section{Discussion}

This paper has quantified the monetary cost of providing surgery at district hospitals in Malawi. Much of this cost is hidden to the general public and to health providers themselves, but identifying the various types of resources used in surgery, the quantities involved and their price tags, and allocating the cost of resources that are shared between the operating theatre and other departments to the appropriate services does enable a better understanding of the main cost drivers of surgery.

\section{Cost of surgery}

The total cost of providing district hospital-level surgery in Malawi in the 2013/14 fiscal year ranged from approximately $\$ 335,000$ to almost twice that amount. The cost of running an OT constituted between 10 and $26 \%$ of the cost of running the entire hospital. The two main cost drivers of surgery are transport and inpatient services (including catering). This is different from hospitals in most highincome countries, where staff salaries are much higher and which use more advanced surgical techniques that involve expensive equipment and materials. In Malawi, in particular, salaries of civil servants are low: the monthly salary of a clinical officer in 2014/15 varied between MWK 115,000 and 150,000, the equivalent of USD 270-350 at the exchange rate at that time (MWK 428 to USD 1).

The large variation in the distribution of costs over different cost centres observed in this study has also been found in other studies [8-11]. The unit cost of a caesarean section in the three hospitals ranged from $\$ 164$ to $\$ 638$, which is higher than the $\$ 133$ reported by Alkire et al. for Malawi in 2008 [12]. Part of this difference might be due to differences in the methodologies that were used, such as allocation of staff time, allocation of transport costs and depreciation of capital costs. The cost of an evacuation from uterus was between $\$ 57$ and \$ 143, which is lower than the $\$ 239$ per patient who received post-abortion care reported by a study in Uganda [13]. The cost of a hernia repair was between $\$ 137$ and \$ 598, which is much higher than the $\$ 59$ found in a study in Uganda [14] but comparable to the $\$ 275$ reported for Ghana [15]. Differences in the cost of inputs for instance salary levels of the staff that performs the surgery (medical offers in Ghana and Uganda; clinical officers in Malawi) make cross-country comparisons difficult. But some of the variation may be explained by differences in methodology: other costing studies allocated cost in a 'top-down approach', which, in comparison with the present study, also involves more assumptions, hence greater uncertainty.

The model that was built and which takes into account the capital and recurrent cost of all the inputs used for the current levels of output (surgery performed, inpatient care provided) allowed for estimates of the cost implications of scaling up surgery at these hospitals-which will be reported in another paper (forthcoming). It is important to note that all three hospitals appeared to have some surplus capacity to realise a certain scale-up of surgery. This surplus capacity existed both at the operating theatres, since they are not open during all weekdays except for emergencies, and the hospital wards, as indicated by the low bed occupancy rates. The case of Nsanje DH is noteworthy: the high cost of surgery in combination with the relatively small number of surgical cases suggests a considerably less efficient surgical care model compared with the other two hospitals. However, the demand for surgery at Nsanje DH appears less predictable in view of its higher proportion of injury-related and emergency and disability-preventive surgery. This may cause peaks in the demand for surgery and for hospital beds, which this study did not seek to explore.

It is also worth noting that a possible scale-up of surgery requires more than just deploying additional surgical staff or allocating a larger budget to the hospital, even if it was ring-fenced for surgery. For instance, the presence of other OT staff such as anaesthetists is also crucial. It is equally important to have a reliable supply chain management in place and autoclaves in good working conditions so as to ensure timely sterilisation of surgical equipment. These functions are not automatically fulfilled in the event of an increase in the budget dedicated to surgery, as has also been demonstrated in studies elsewhere [16, 17]. A qualitative study amongst medical licentiates who deliver surgery in Zambia, also conducted as part of COST-Africa (another paper by Gajewski et al., forthcoming), showed that task shifting of surgery may be a sustainable response to the unmet surgical needs of rural populations, but it needs to go together with professional recognition, suitable employment conditions and career paths and opportunities of the cadres involved.

Broadening the range and scaling up the volume of major surgery conducted at district hospitals would most likely lead to fewer surgical referrals from district to central hospitals. Apart from the positive health effects this might have [Gajevski et al., forthcoming], it would also 
imply certain savings, especially on ambulance transport for the evacuation of emergency cases; and less expenditure on the side of central hospitals, where fewer cases of surgery might be expected.

While surgery has for a long time been perceived as complex and expensive, there is now good evidence that many essential surgical interventions can be provided in a cost-effective manner in resource-poor countries $[1,3,14-18]$. Quantification of the monetary cost of providing surgery is essential in the pursuit of expansion and scale-up of surgery in countries where the needs for lifesaving and disability-preventive surgery are unmet. It responds to the call from the Lancet Commission on Global Surgery for LMIC-specific research to investigate how domestic or external funding of surgical care can be used to improve efficiency and performance, and achieve economies of scope and scale with optimum returns on investment. For a typical district hospital in Malawi, we can now calculate the extra budget requirements, and this information may be used at the national level, along with organisational, ethical and political arguments to scale up surgery, so as to eventually meet clinical demand and improve health and welfare. The Lancet Commission has argued that, rather than looking at the extra budget requirements for scaling up surgery as a cost, one should view them as an investment, because of the associated economic gains [3].

This paper has not considered the costs that are often borne by patients to access surgical care, and which for some patients may be catastrophic. To elicit such data, a survey was conducted as part of the COST-Africa project, amongst patients who had undergone surgery at district hospitals and one of the central hospitals in Malawi. The results will be reported separately [Bijlmakers et al., forthcoming], demonstrating that increased access to surgery for rural populations has economic benefits for the patients involved and their families.

\section{Strengths}

This study resulted in a model that allows an automated calculation of the cost implications of different resource inputs of changes in prices and of different scenarios for scaling the delivery of surgery. This makes it a powerful tool. It also enables the calculation of possible savings that can be made if certain resources were used differently (for instance by reducing ambulance trips), and how much extra budget would be required to increase the number of surgical procedures that are undertaken. The model further makes it relatively easy to replicate the study and conduct similar costing studies in other hospitals.

\section{Limitations}

Heterogeneity, uncertainty regarding the robustness of some of the estimates and some model uncertainty related to the criteria used for allocating costs are the main limitations of the study. This is not uncommon in this kind of studies [19]. For example, for the allocation of staff time to surgery, which was based on interviews, uncertainties remained about staff not always being on-site and available, which may also have affected the continuity and quality of services. The absence of hospital staff may happen for various reasons, including workshop attendance, family matters and moon lighting, but reports are often anecdotal [20]. Heterogeneity in the use of drugs and other medical supplies in surgery and in the use of transport cost may also be worth exploring further.

\section{Policy implications}

This study has provided insights into the economic efficiency of health care facilities and had laid a basis to calculate the financial requirements for a possible scaling up of district-level surgery. Hospital managers and national health policy makers may want to take the economies of scale into account and weigh the additional cost of scaling up surgery at district hospitals against the health benefits as well as the savings that would be made. The low bed occupancy rates suggest overcapacity and a potential to reduce the number of beds, reorganise wards and/or reallocate staff, or depending on the catchment population and alternative service providers that may be available, it may point to avoidance of treatment seeking by the population concerned. Staff deployment would need to be seen in relation to the seasonality of certain pathologies and in people's treatment seeking behaviour [21, 22]. Extension of patients' duration of stay at the hospital beyond what is required from a medical perspective, as might have been the case in one of the hospitals involved in this study, would need to be discouraged so as to avoid the extra expense.

Further research on the cost of scaling up surgery may inform policy choices, especially if such studies consider the possible changes in patient flows and referral patterns when the range of surgical procedures performed at rural district hospitals is expanded.

Acknowledgements The COST-Africa project was funded by the European Union-7th Framework Programme for Research and Technological Development Grant, Ref: FP7-AFRICA-2010, grant agreement number 266417. The authors wish to acknowledge the support of the Ministry of Health in Malawi, the College of Medicine of the University of Malawi, and the hospital management teams and clinical officers of the three hospitals involved in the study for their 
time and effort to provide data. We thank Henk Broekhuizen-Versteeg, from Radboud UMC, for helping to finalise the manuscript.

\section{Compliance with ethical standards}

Conflict of interest No potential or real conflicts of interests are declared.

Open Access This article is distributed under the terms of the Creative Commons Attribution 4.0 International License (http://crea tivecommons.org/licenses/by/4.0/), which permits unrestricted use, distribution, and reproduction in any medium, provided you give appropriate credit to the original author(s) and the source, provide a link to the Creative Commons license, and indicate if changes were made.

\section{References}

1. Alkire BC, Raykar NP, Shrime MG et al (2015) Global access to surgical care: a modelling study. Lancet Glob Health 3:e316e323

2. Shrime MG, Bickler WS, Alkire BC et al (2015) Global burden of surgical disease: an estimation from the provider perspective. Lancet Glob Health 3:S8-S9

3. Meara JG, Leather AJM, Hagander L et al (2015) Global Surgery 2030: evidence and solutions for achieving health, welfare and economic development. Lancet 386(9993):569-624

4. van Amelsfoort J, van Leeuwen P, Jiskoot P et al (2010) Surgery in Malawi-the training of clinical officers. Trop Doctor 40(2):74-76

5. Chilopora G, Pereira C, Kamwendo F et al (2007) Postoperative outcome of caesarean sections and other emergency obstetric surgery by clinical officers and medical officers in Malawi. Hum Resour Health 5:17

6. Shepard DS, Hodgkin D, Anthony YE (2000) Analysis of hospital costs: a manual for managers. World Health Organization, Geneva

7. Conteh L, Walker D (2004) Cost and unit cost calculations using step-down accounting. Health Policy Plan 19(2):127-135

8. Evans CT, Lenhart P, Lin D et al (2014) A cost analysis of pediatric cataract surgery at two child eye health tertiary facilities in Africa. J AAPOS 18(6):559-562
9. Saronga HP, Duysburgh E, Massawa S et al (2014) Efficiency of antenatal care and childbirth services in selected primary health care facilities in rural Tanzania: a cross-sectional study. BMC Health Serv Res 14:96

10. Dalaba MA, Akweongo P, Savadogo G et al (2013) Cost of maternal health services in selected primary care centres in Ghana: a step down allocation approach. BMC Health Serv Res 13:287

11. Petrou S, Gray A (2011) Economic evaluation using decision analytical modelling: design, conduct, analysis, and reporting. BMJ 342:d1766

12. Alkire BC, Vincent J, Turlington Burns C et al (2012) Obstructed labor and caesarean delivery: the cost and benefit of surgical intervention. PLoS One 7(4):e34595

13. Vlassoff M, Mugisha F, Sundaram A et al (2014) The health system cost of post-abortion care in Uganda. Health Policy Plan 29(1):56-66

14. Löfgren J, Mulowooza J, Nordin P et al (2015) Cost of surgery in a low-income setting in eastern Uganda. Surgery 157(6):983-991

15. Shillcutt SD, Clarke MG, Kingsnorth AN (2010) Cost-effectiveness of groin hernia surgery in the Western Region of Ghana. Arch Surg 145(10):954-961

16. Chao TE, Sharma K, Mandigo M et al (2014) Cost-effectiveness of surgery and its policy implications for global health: a systematic review and analysis. Lancet Glob Health 2:e334-e345

17. Gallaher JR, Mjuweni S, Cairns B et al (2015) Burn care delivery in a sub-Saharan African unit: a cost analysis study. Int J Surg 19:116-120

18. Grimes CE, Ang-Henry J, Maraka J et al (2014) Cost-effectiveness of surgery in low- and middle-income countries: a systematic review. World J Surg 38(1):252-263. doi:10.1007/s00268013-2243-y

19. Shrime MG, Alkire BC, Grimes C et al (2017) Cost-effectiveness in global surgery: pearls, pitfalls, and a checklist. World J Surg. doi:10.1007/s00268-017-3875-0

20. Cumbi A, Pereira C, Malalane R et al (2007) Major surgery delegation to mid-level health practitioners in Mozambique: health professionals' perceptions. Hum Resour Health 5:27

21. Hlimi $T$ (2015) Association of anemia, pre-eclampsia and eclampsia with seasonality: a realist systematic review. Health Place 31:180-192

22. Ewing VL, Lalloo D, Phiri K et al (2011) Seasonal and geographic differences in treatment-seeking and household cost of febrile illness among children in Malawi. Malaria J 1(10):32 